\title{
Counterfactual scripting. Challenging the temporality of participation
}

This paper discusses counterfactual scripting to critically inquire and give form to Participatory Design (PD) processes in an age of ubiquitous participation. In its often superficial application in various societal domains, the processes and instruments for participation are often cut loose from their political context.

The stories of what has happened in a PD process are told through a clear storyline that develops logically via different design moves towards a well-defined plot; leaving out any alternative narratives. Inspired by counterfactual history, we reject this teleological perspective and explore counterfactual scripting as a way to give renewed attention to the political context in PD. We do this by giving form to the design process as a pluralistic process that not only focusses on the future, but creates alternatives for the past to speculate about the future. We evaluate counterfactual thinking in a participatory architecture and urban planning process.

Keywords: participatory design, codesign, counterfactual scripting, design decisions

\section{Introduction}

Participatory Design aims for a democratic process in which designers and those affected by design create and make design decisions together. Writing about spatial planning Arnstein (1969) describes participation as: "The redistribution of power that enables the have-not citizens, presently excluded from the political and economic processes, to be deliberately included in the future". Scandinavian PD researchers in the 1970s defined participation in function of including workers in deciding on the design and use of workplace computer applications (Ehn 1988). A large focus of PD study in this workplace tradition is based on the study of methods; what specific tools and practices support the involvement of participants in the design process. Other research takes PD to new application domains, away from the traditional PD in workplacesconcept (see Halskov and Hansen 2015). We perceive counterfactual scripting (CS) as part of the fifth category Halskov \& Hansen identify in PD research. The research belonging to this category studies the basic concepts of PD rather than focusing on specific methods, a new application domain, technology or theory. In our research, we focus on time (past, present, future) as a catalyst for the PD process. This fifth category is also the one where Halskov \& Hansen see the most debate on the political aspects of participation. Counterfactual scripting wishes to subscribe to this political tradition of 
$\mathrm{PD}$, zooming in on the relation between design decisions and time. This project can also be seen as part of the community based PD (alongside the more 'traditional' workplace based PD). In this project, counterfactual scripting is used as a way of thinking wherein PD is used for public deliberation where the plurality of the community members' voices (in this case the small town of anonymous location) can be heard. As Sanoff (2008) indicates, deliberation asks for "careful consideration of an issue, examining the facts, viewpoints and consequences related to it". We use time as a catalyst for this deliberation.

Both in the workplace tradition as well as in community based PD, the process of shared decision-making can easily be curtailed towards a limiting focus, that of making and narrowing down choices together in a straight line towards a common goal, potentially obscuring the political context (De Bie, Oosterlinck, and De Blust 2012). This straight line becomes evident when designers tell the (hi)story of what has happened in their design process in the form of a clear storyline that develops logically via different design moves towards a well-defined plot. To avoid this instrumental approach, we need to broaden the view on where and when decisions are taken in PD. PD researchers often report on single design activities and leave out the interpretation, planning and decision-making that takes place in-between events (Andersen et al. 2015). In the context of community-based PD it is important to enhance researchers' reflexivity about how PD processes facilitate the sharing of decision-making with participants in different (not necessarily sequential) 'design moves' over time; how decisions taken before the project (structural elements, e.g. organisations' commitments) give form to the design space and how many decisions are irrational, involve chance and serendipity (Bratteteig and Wagner 2014).

This paper's aim is to broaden the design space of PD in a temporal sense by challenging the teleological perspective and investigating causal pluralism: "the view that causation is not a single kind of relation or connection between things in the world" (Godfrey-Smith 2009). This view relates closely to PD's concern to create situations through which pluralism manifests itself productively (Di Salvo, Clement, and Pipek 2012). Pluralism refers to design decisions that were not taken, but were as plausible to occur as those portrayed in the dominating story. The interest in pluralism inspired us to investigate counterfactual historiography (Ginderachter, Aerts, and Vrints 2015), a frame of thinking that suggests going back in time to rewrite what has happened and 
speculate about plausible what if- scenarios. Since PD is not exclusively interested in plausible what if- scenarios of the past, but suggests a future perspective, we explored and evaluated how this frame can enhance pluralism in a design context: speculating on the consequence of the what if in the past for the what will be. We investigated this via the term 'counterfactual scripting' which looks at how existing stories on decisionmaking in design (e.g. in case studies) can become a starting point to create these what if-stories. Our research question was therefore: 'How can counterfactual scripting serve as a frame of thinking for designers and participants in a PD process to articulate and explore alternative decisions in the past and thus in turn inspire pluralistic views on the future?'

\section{Counterfactual thinking}

The philosophy of Lewis (1973) foregrounds counterfactual thinking as similar to if... then logics, in which possible worlds are created that are materially and hierarchically similar to the actual world, but spatially or temporally unconnected. Counterfactual historiography represents these possible worlds as probable but unrealised alternatives of history. In a what if-history the focus on plausibility is central: what if Gorbachev had never been elected? What if Hitler had been fatally wounded in the Great War? How would this have changed the face of modern Europe? These questions also pop up in daily life: what if I had never met my partner? The added value of this way of thinking is to learn: decisions about the future are based on what is versus on what might have been or what if; continuously comparing the actual outcomes of what we did with alternative scenarios. Looking back in time in our personal life, in world history or in a design process often begins from a belief in a linear chain of causation, a deterministic or teleological perspective, to add meaningful direction or purpose to the events: the past had to inevitably lead to the present. However counterfactual history believes in causal pluralism, the idea that there is no single cause (Hitchcock 2007). By presenting what if-relations or alternatives to the actual past, CS supports a better understanding of the what is (present) and the what will be (future).

Essential in counterfactual history are the turning points; moments in history when the course of things could have been pulled in different directions: revolutions, battles, inventions or the birth of a child. A counterfactual intervention in these turning points begins from a minimal rewrite of the past that sets an alternative scenario in 
motion. CS starts from plausible non-facts, not from improbable ones (Ferguson 2000), as is the case in fictional counterparts such as fantasy (steampunk, historical fantasy, etc.) or science fiction (time travel novels, space westerns, etc.). Lebow (2007) indicates that the plausibility of a counterfactual statement can be evaluated via its theoretical consistency (empirical findings, theories or assumptions it is based on) or clarity (specifications of its conditions). In creating a plausible counterfactual history, one dissects the interplay between who is acting (the agency of actors), how pivotal the macro-structure is and in what way coincidence influenced the cause of events.

In design contexts, counterfactual thinking can be found in design fiction and speculative design cultures that use material constructs (media design) to create visions of the future: a "discursive space within which new forms of cultural artefact (futures) might emerge" (Hales 2013). Gonzatto et al. (2013) state that design fiction as practiced in future technological scenarios often is too utopian or depicts the future as a continuity of the present status quo, instead of a social change. They state that designers can use materiality to open up these scenarios to a broader audience in a participatory process, which allows to move from naive to more open-ended critical alternatives for the past, present and future. Building on Pinto Gonzatto et al. use the term 'handiness' to emphasise that when designers present artefacts depicting the future or the past, they are acting in the current social order. As the models or drawings stimulate imagination and discussion, this kind of material speculation has a tradition in architecture and urban planning (Lukens and DiSalvo 2011). Wakkary et al. (2015) dive deeper into this concept of material speculation by exploring counterfactual artifacts as specially and professionally crafted material artifacts that operate and exist in the actual world and generate possible worlds through encounters with people: "the world(s) as imagined by the designers, world(s) imagined by those who encounter the counterfactual artifact, and most speculatively, the counterfactual artifact itself can be understood to imagine a world" (Ibid., p 100). The counterfactual artifacts in this way make room for consequential pluralism, offering an outlook on how the confrontation with the artefact in the present has multiple consequences in the future.

Both counterfactual history and design fiction stress plurality and use defamiliarisation to upset things in a productive way by showing a speculative future or past to make explicit how the present is linked to choices made in the 'actual' past and future. What counterfactual history contributes to within participatory contexts is its interest in reality; a plausible alternative of the actual, instead of design-fiction's overall 
interest in the non-factual. While counterfactual history stresses verbal forms to make alternatives tangible, design fiction stresses a materialisation through an artefact, which makes it relate to PD. However, describing the (in-between) outputs from a PD process as 'written accounts' or 'artefacts' is limiting, as the human role - typical to participatory processes - stays out of focus. Many PD researchers have therefore found inspiration in Science and Technology Studies (STS) to define the design process as 'drawing things together' or giving form to socio-material assemblies, involving both people and objects (Binder et al. 2011). It is also in STS literature that the term script is used to describe the result of people inscribing objects with their visions on the world (Akrich 1992). STS defines scripting as a descriptive study of human and non-human relations (e.g. in buildings or information systems). We use it in a constructive manner to describe how designers can combine both humans and objects in scripts that construct publics (i.e. dynamic groups that form around a shared issue) on societal issues and invite people to take action (DiSalvo 2009). Combining the idea of scripting with the acquired insights from counterfactual thinking in history and (participatory) design (for an overview of the characteristics of counterfactual scripting and neighbouring terms, see figure 1), we propose that the following elements play a role in counterfactual scripting in PD:

(1) Turning points: Designers and participants collaboratively identify turning points in the history of a community involved in a PD process to draft a pluralistic view on the past of the design process: moments where it is plausible that the course of things could have taken a different direction.

(2) Minimal rewrites: Designers and participants do minimal rewrites of these turning points into plausible what ifs or alternative socio-material assemblies. To support their plausibility, the rewrites are coupled with an argumentation which makes transparent to readers how the rewrites are affected by decision-making preceding the PD process; the personal role of actors (who is acting), the overarching macro-structure and in what way a course of events is influenced by coincidence and personal choices.

(3) Materialisation: Designers and participants craft the minimal rewrites of turning points in socio-material assemblies that gather past and future into a slightly defamiliar present. This upsets the temporal dimensions but also provides a productive way forward for the future participatory process. 
(4) Confrontation: The confrontation with the counterfactual scripts and their argumentations give researchers and participants an overview of and access to a variety of consequences of the scripts in the future. The defamiliar character of the script (what is real, what is counterfactual?) supports those confronted with the scripts in speculating on alternative futures for their community. For the researcher, the materialisation of the rewrites makes explicit the personal role of actors, the role of macro-structures and coincidence in decisions in the past and how they can play in the present and future.

Before moving to the next section and elaborating on the use of CS in PD it is important to indicate that these four elements offer researchers and participants a way of thinking about a design process, but do not define specific methods, tools or techniques to translate this into practice. To make this step we can make use of a rich tradition in PD in which fictional elements are used to open up the design space. As Dindler (2010) indicates, one central characteristic of PD is the creation of a fictional space where 'what is already there' combines with the unknown, transcending what exists. Dindler argues that this fictional space is established through "participants practicing games of make-believe mediated by props". It is in this line of thinking that counterfactual scripting should be perceived: as a frame of thinking that uses time as its catalyst to create this fictional space. Blythe and Wright (2006), for instance, describe a PD process wherein pastiche scenarios (written by the researchers) are used to engage participants to take part in the design process by debating the contents of the scenarios. Forlano and Mathew (2014) combine design fiction and PD to move towards futureoriented conceptualisation of a smart city.

Figure 1. Counterfactual scripting and neighbouring terms

\section{Counterfactual scripting in Participatory Design}

In (anonymous location) a group of citizens gathered to discuss certain issues in the planning and design of their town, in relation to a residential expansion. Over the previous ten years they had been involved in spatial studies concerning this issue, but were disappointed by the confusing communication between different groups (e.g. citizens, property developers and policy makers) involved and desired a more transparent decision-making process. In 2014 the citizens asked our research group to 
re-open communication between these actors, for which we (two PD researchers and authors of this article) decided to explore counterfactual scripting. We decided to use counterfactual scripting in this participatory spatial planning and design project (that -as indicated above- can also be situated in the tradition of community-based PD) as the time-aspect was a key variable. To demonstrate the different steps in the scripting process, we focus on one particular aspect of the case: a local bridge.

\section{(1) Turning points: decisive moments in the past}

To gain insight in the turning points in the history of this case study, the research team, together with a group of inhabitants from (anonymous), invited people from the community to participate by spreading flyers and knocking on people's doors. The responding participants were involved in local private companies such as a local bar, an influential mobile provider and a local store; adolescents with an interest in the youth centre, ecological themes and spaces for hanging out; newcomers to the village - mostly young parents; local policy representatives; architecture students, 2 media artists and 3 PD researchers. The participants were asked to bring in archival material that they found relevant to collaboratively decide on the important turning points in the history of the community for the spatial planning and design process during co-design workshops over the course of two weeks (Sanders and Stappers 2008). During these workshops the collected archival material was translated into mood-boards and diary fragments to tell stories on decision-making in the past and present. The diary fragments provided a personal way to express one's story on decision-making (personal turning points) and the mood board helped in establishing a general group feeling and had the specific goal of being explicit about the 'important' turning points of the previous ten years of spatial planning in the town. A combination of both techniques attempted to find a balance between opening up for conflicting interests and perspectives on the past and supporting the search for a common base (the set of turning points) to work on, shared by all. The different turning points were placed on a timeline and collaboratively the participants decided which they wanted to rewrite with an eye on the future. Participants agreed to select events that they still had a personal connection with and all (except the first) did not go back more than 10 years in time:

(1) Before 2004: In WOII the old bridge which connected two sides of the village is bombed and remains a point of discussion in the community. The 
diminishing church community in the past decades also continuously defines debates on spatial planning/design in the community.

(2) 2004: MOVE, a citizen-driven cultural and sports event reflects on the village's mobility, green, parking spaces, recreation, school and services.

(3) 2008: A spatial structure plan commissioned by (anonymous location), concluding that residential expansion was necessary, but should take in account the remarks of the citizens regarding green, mobility, parking, recreation, school and services.

(4) 2013: A regional spatial implementation plan decides for an increase of households in (anonymous location). It was consulted/objected during 60 days and announced via a public declaration printed on posters in the neighbourhood.

(5) February 2014: inhabitants signed a notice of objection about the implementation plan.

(6) May 2014: (anonymous) asks our research group to supply them with an approach to confront and document the different agendas at stake.

(7) November 2014: the citizens and our research group set up co-design workshops to create spatial scenarios for the village in 2024. Policymakers feel uncertain about how to handle the case and do not participate.

(8) September 2016: a new participation trajectory starts with the city, the citizens and the research unit involved in the described research trajectory.

\section{(2) Minimal rewrites: rewriting decisions in the past leading to counterfactual futures}

During the co-design sessions, we as PD researchers (one former journalist) guided the minimal rewrites of the described turning points in the past to script future scenarios for 2024. Because the participatory process aims for a transparent and broad public debate; the researchers and participants used a newspaper as a vehicle for the minimal rewrites. We created an editorial board with a group of 30 people in the local bar, to collate the minimal rewrites into a semi-fictional newspaper and formed smaller groups of around 7 participants to deal with one newspaper article each. Two questions served as a lead: What documented stories on decision-making in the past do we want to bring to the table? and, What are the turning points in these stories? We supported the participants in doing the minimal rewrites of turning points in the past in the form of articles (or scripts) that inform readers about a desirable future, imagining how the citizens would 
like to live in (anonymous location) in ten years (the newspaper is dated in 2024). They were asked to be explicit about the structural factors (e.g. the founding infrastructures, organisations, policy levels involved), personal actions (the role of individuals) or coincidental factors (beyond individual choices or structures) related to the turning point.

One group of participants did a minimal rewrite of an early turning point (2) in the history of the spatial planning process, namely the MOVE initiative. To continue this citizen self-organised event, this group imagined that a cooperative called 'CityDepot (anonymous location)' was founded with the goal to connect two parts of the village via a bridge to transport, display and sell local goods and services. The bridge would host a cooperative that would organise a local market and a slow biking/walking connection. The factual - less central - location of the current bridge, was replaced by a counterfactual cooperative operating via a bridge in the centre of the village. Another important reference for this script is the current absence of a bridge between two sides of the village (turning point 1). The original connecting bridge was destroyed in WWII and replaced by a ferryboat until the boat sunk, resulting in 35 children drowning. This drama still impacts the community to the present day, and, when reflecting with members of the community on its past, this event comes to the foreground as both as an actuality of importance and as a drama that is still part of families' (hi)stories (further evidenced in 2016 by a theatre play dramatisation which looked at how humans deal with collective trauma). Between 1977 and 1979 a new bridge 'Tuikabelbrug' was created at a less central location, intended to serve as a connection for a fast road between two main cities in the region. However, the road was prevented from being fully implemented and the bridge is hardly used. In the past, there had been calls to have a new, more central (biking) bridge between two parts of the village. It is probable that at the time of planning the Tuikabelbrug, policy makers could have chosen to replace the bombed bridge for a more central biking bridge which would have reconnected the community.

\section{(3) Materialisation: processing minimal rewrites in material outcomes}

During the co-design 'scripting' sessions, the PD researchers guided the participants in materialising (writing and crafting) the scripts/articles to function as a catalyst for constructing publics on the issue. They asked the participants to first make a collage of archival material and their ideas about the future and then create one image per article 
by performing the scripts in the spatial context of the village in the form of a still image, a 'tableau vivant', and photographing it. We offered the participants a set of props to use in the performance: random objects and white billboards, both empty or imprinted with a few symbols (a sun, a bomb, etc). The scripts were embodied by the participants, activating them to enact these future ideas in their everyday spatial context. The minimal rewrites were processed in a Do-It-Yourself newspaper template we created beforehand, which gave the newspaper a professional and activist aesthetic, using black and white images, very large titles and a newspaper cover stating: 'The Future is Today'.

The script on the cooperative model was strongly defined by the participation of one of the former representatives of MOVE (focusing on citizen-driven organization), the owner of the mobile provider (interested in innovative entrepreneurship) and participants concerned about 'slow' and green biking connections. The participants gave one of the locally known activists for rebuilding the old bridge the role of CEO of Citydepot to stimulate recognition in the community. Figure 2 shows how in the first scripting exercise the participants made a collage of archival material (the devastating event of the drowned children) and their desires for the future. Figure 3 shows the resulting newspaper article and how the participants materialised the script by picturing the bridge with a clothes hanger and a billboard of a sun.

Figure 2. Scripting process of 'Citydepot (anonymous location)'

Figure 3. Newspaper article of 'Citydepot (anonymous location)'

\section{(4) Confrontation: provoking pluralistic readings of the scripts}

The resulting newspaper, encompassing minimal rewrites of a participatory process that started in 2004, co-design workshops in 2014 and imagined actions in 2024 that were presented as if they took place today, was spread on paper in the region, presented in two exhibitions and shared via social media. The newspaper constructs publics via a slightly defamiliar experience, as people reading it are unaware of what actually happened: Which information is from the past and which are future projections?; What is real and what is counterfactual?; thus it opened up the newspaper for pluralistic readings. This provoked mainly positive responses, but some politicians perceived it as an attack on their current policy and wished not to support the spread of the newspaper while others embraced the issues raised. 
The materialisation of the script on the bridge - using the hanger and the sun inspired an initiative after the newspaper was spread. The citizens organised several sunrise brunches on the 'Tuikabelbrug' to gather and mobilise citizens to support and set up food markets on the bridge. The scripting process during the project offered the participants a critical space to revisit important, but also contested events in the past (the unfortunate event of the drowning of the children). At the same time, the controversies on the consequences of revisiting a contested past - recreating this bridge - were addressed too briefly in the scripts. Embracing multiple voices in the past as an inspiration for the future, could have invited the participants of the project to more explicitly explore multiple voices about the consequences of these proposals in the scripts (e.g. the probability of an increase of traffic, once a new bridge is installed)?

\section{Evaluating the role of counterfactual scripting}

Based on a qualitative clustering of follow-up interviews and workshops with the participants and critically discussing the PD process, we offer some reflections on the role counterfactual scripting can play and go deeper into a way to evaluate counterfactual scripting.

For the community involved in the project described, this frame of counterfactual scripting seemed to work on two levels. First it helped some individual citizens to take small steps in setting up initiatives for the benefit of the community (from the organisation of brunches intending to stir the feeling of belonging to the first steps in actually setting up the above-mentioned cooperative) and, secondly, participants indicated their changed perspective on the complexity of participatory processes and the role individuals' and the community's history can play in these. Next to this, local politicians, inspired by the community's participation decided to fund a long-term participatory trajectory on the residential expansion, taking the issues in this project as a starting point.

Counterfactual thinking is a way of reshaping the past in function of the future of a design process. We found it important to foreground a way to qualitatively evaluate how counterfactual scripting informs the PD process, also to avoid researchers to use it as an excuse for freewheeling or manipulation of the past in function of a desired future. In this process, we use trustworthiness and authenticity as guiding concepts, since they are frequently used in Participatory Action Research (Lincoln and Guba 1985) and are a 
good alternative to the more discursive concept of plausibility as an evaluation principle in counterfactual history.

Trustworthiness is traditionally evaluated by questioning if the research is based on multiple sources and if the personal lens of the researcher is made explicit (Ibid.). The counterfactual scripts revealed a diversity of viewpoints and human interests in a certain history and envisioned future; including the past, the voices that are addressed in a design process multiply. Accounting for a plurality of voices in the PD process via the scripts, allowed the participants to reflect/act on their own roles and responsibilities in decisive moments, in relation to other people's roles, but also to the involved nonhuman actors. The case also made clear that there exists a productive tension between the quantity and the quality of voices. During the fieldwork, participants elaborated on one person's voice (the appointed CEO of the fictive cooperative) to provide more insight in a design decision and to enhance this person's recognisability and responsibility in the process. However, researchers were aware of the potential threat of dominant voices who might influence the rewriting process too strongly. In this sense, future research needs to search for ways to, in the rewrites, assure the plurality of voices.

Authenticity is generally reviewed by looking at how participants are involved in the decision-making process and in taking up new courses of action (Ibid.). We want to state that evaluating authenticity does not imply using counterfactual scripting as a formula to guarantee participation in decision-making. In lengthy processes, this would lead to disappointed participants. Nevertheless, we propose that paying attention to authenticity allows PD researchers to evaluate how the PD process constructed publics on the issues at stake. In follow-up interviews, the participants indicated that the counterfactual scripting process enriched and intensified their critical view on and engagement in the different courses that the participatory process could take. The minimal rewrites of turning points in the PD process allowed for creating design proposals as sources of public debate on past, present and future, instead of end-points or solutions. The newspaper allowed the construction of new publics (neighbours, policy makers, architects,...) around the issue of the bridge. By using bodily performance (through the enacting of the scripts; the staging of the bridge with the participants who created the rewrites) in the scripting process, non-designers became an active part in concretising the spatial proposals (e.g. choices of issues and locations to 
address) and the newspaper became a more indirect informant of the policy meetings or news media.

However, the discussed cases also show that - while the tone of the scripts can be critical and imaginative, constructing publics required the PD researchers to actively prepare and guide a constructive writing and crafting process. In this case the collaborative systems were characteristic of a research or journalism practice; reviewing each other's content, fact checking or doing field work to fill in missing information.

This constructive character was achieved in two ways:

Firstly, elaborating on decisive moments in the past of a participatory process opens up space for the participants to create critical design proposals that dare to refer back to important and often contested events in time. However, the scripts should not only focus on the mistakes or contested decisions of the past which would endlessly stall the design process or irritate its actors. Revisiting contested past(s) benefits from including discussions about the constructive activity of redesigning this past in function of the future. In this case this involved talking about how to create a cooperative or people's emotional connections to decisions made in the process.

Secondly, the role of crafting matters of concern in tangible design proposals played a great role in constructing publics on the PD process. The performances in public space to create photographs that accompanied the articles were situated prototypes of the future. Like design fiction, the attraction to these prototypes is related to how well their defamiliar character was crafted. Their mixed situatedness in today's world experience and in possible futures as well as their subjective and plural engagements with the past made them inviting and entertaining for people to engage with.

While this evaluation shows that counterfactual scripting has clear benefits for the PD process, its extensive engagement with the past raises new challenges that need further research. Involving the complexity of the past can blur the focus of PD processes in offering people a space for sharing power in decision-making about the future. It can remind people of past conflicts and in that sense potentially inhibit a productive design process. Exploring the plurality of the past thus comes with responsibilities in revealing the plurality of the consequences of addressing this past. By presenting the scripts as matters of concern that inspire alternative choices, they are not considered a tool for conflict analysis, but as a way of giving form to a project that allows disagreement. For presenting, the medium itself is very decisive in how this matter of concern is shared: 
the newspaper provided room for critical discourse, but the short length of the articles also obscured many details.

\section{The role of counterfactual scripting in participatory design}

In summary, counterfactual scripting, by questioning truth and a single voice in design, offers interesting pathways to explore for PD research in an age where the ubiquity of participation can lead to depoliticisation of participation. PD is easily depoliticised by being a pragmatic process or by a focus on tools (De Bie, Oosterlinck, and De Blust 2012). The described case shows that by looking back on the plurality of the community's past and the analyses of the various personal choices, structural factors and coincidences the political comes back to the foreground. This became evident in the response of the local politicians who were provoked by the issues tackled or embraced the community's counterfactual scripts.

As a 'frame of thinking' counterfactual scripting allows PD researchers and participants to more actively use the temporality of a design process and decisions in the past as resources for speculating on alternative decisions in the past. This inspires pluralistic what if-views on the future instead of seeing time as only an instrumental tool (following a series of design steps taking a project from start to finish). CS tries to support the debate on causality and time, regardless of the methods or techniques used to stimulate this debate. This is particularly interesting in community-based PD processes, in which long, diverse and complex histories may play a role.

Counterfactual scripting does not propose a radical shift in framing PD. Instead it inscribes itself in a tradition in PD in defining and giving form to design as a political process: a socio-material assembly, a contested 'thing', making use of what ifs. It supports - or reminds - PD researchers to inform and inspire these what ifs by pluralism throughout the whole process.

To conclude we can say that counterfactual scripting challenges the temporality of the participatory design process. It offers a pluralistic view that allows designers and participants to collaboratively give form to what ifs, while offering them the opportunity to steer the design space in order to reach some kind of closure. It takes into account the structural factors, the personal choices and coincidental factors that define turning points in a specific design history to inform future design decisions. Counterfactuals require a deep engagement with challenging decisions from the past and are a resource to design a pluralistic future. 


\section{References}

Akrich, Madeleine. 1992. "The de-Scription of Technical Objects.” Shaping Technology/Building Society, 205-24.

Andersen, Lars Bo, Peter Danholt, Kim Halskov, Nicolai Brodersen Hansen, and Peter Lauritsen. 2015. "Participation as a Matter of Concern in Participatory Design." CoDesign 11 (3-4): 250-61. doi:10.1080/15710882.2015.1081246.

Arnstein, Sherry R. 1969. “A Ladder of Citizen Participation.” Journal of the American Institute of Planners 35 (4): 216-24.

Binder, Thomas, Giorgio De Michelis, Pelle Ehn, Giulio Jacucci, and Ina Wagner. 2011. Design Things. MIT Press.

Blythe, Mark A., and Peter C. Wright. 2006. "Pastiche Scenarios: Fiction as a Resource for User Centred Design.” Interacting with Computers 18 (5): 1139-64. doi:10.1016/j.intcom.2006.02.001.

Bratteteig, Tone, and Ina Wagner. 2014. Disentangling Participation. Computer Supported Cooperative Work. Cham: Springer International Publishing. http://link.springer.com/10.1007/978-3-319-06163-4.

De Bie, Maria, Stijn Oosterlinck, and Seppe De Blust. 2012. "Participatie, ontwerp en toe-eigening in een democratische stadsvernieuwing." In Stadsvernieuwingsprojecten in Vlaanderen (2002-2011) : een eigenzinnige praktijk in Europees perspectief, 29-33. ASP nv. http://hdl.handle.net/1854/LU2100027.

Di Salvo, Carlo, Andrew Clement, and Volker Pipek. 2012. "Participatory Design For, With, and By Communities." In International Handbook of Participatory Design, 182-209. Oxford: Routledge.

Dindler, Christian. 2010. “The Construction of Fictional Space in Participatory Design Practice." CoDesign 6 (3): 167-82. doi:10.1080/15710882.2010.493941.

DiSalvo, Carl. 2009. "Design and the Construction of Publics." Design Issues 25 (1): $48-63$.

Ehn, Pelle. 1988. "Work-Oriented Design of Computer Artifacts.” Umeå, Sweden: Umeå University. http://www.divaportal.org/smash/record.jsf?pid=diva2\%3A580037\&dswid=4636.

Ferguson, Niall. 2000. Virtual History: Alternatives and Counterfactuals. Basic Books. Forlano, Laura, and Anijo Mathew. 2014. "From Design Fiction to Design Friction: Speculative and Participatory Design of Values-Embedded Urban Technology." 
Journal of Urban Technology 21 (4): 7-24.

doi:10.1080/10630732.2014.971525.

Ginderachter, Maarten van, Koen Aerts, and Antoon Vrints. 2015. Het land dat nooit was: een tegenfeitelijke geschiedenis van België. Bezige Bij.

Godfrey-Smith, Peter. 2009. “Causal Pluralism.” In The Oxford Handbook of Causation, edited by Helen Beebee, Peter Menzies, and Christopher Hitchcock, 326-337. Oxford University Press.

Gonzatto, Rodrigo Freese, Frederick M. C. van Amstel, Luiz Ernesto Merkle, and Timo Hartmann. 2013. "The Ideology of the Future in Design Fictions.” Digital Creativity 24 (1): 36-45. doi:10.1080/14626268.2013.772524.

Hales, Derek. 2013. "Design Fictions an Introduction and Provisional Taxonomy." Digital Creativity 24 (1): 1-10. doi:10.1080/14626268.2013.769453.

Halskov, Kim, and Nicolai Brodersen Hansen. 2015. "The Diversity of Participatory Design Research Practice at PDC 2002-2012.” International Journal of HumanComputer Studies 74 (February): 81-92. doi:10.1016/j.ijhcs.2014.09.003.

Hitchcock, Christopher. 2007. "How to Be a Causal Pluralist.” In Thinking About Causes: From Greek Philosophy to Modern Physics, edited by Peter K. Machamer and Gereon Wolters, 200-221. Pittsburgh, PA: University of Pittsburgh Press. http://resolver.caltech.edu/CaltechAUTHORS:20140407164135612 .

Lebow, Richard Ned. 2007. "Counterfactual Thought Experiments: A Necessary Teaching Tool." The History Teacher 40 (2): 153-76. doi:10.2307/30036985.

Lewis, David. 1973. Counterfactuals. Blackwell Publishers.

Lincoln, Yvonna S, and Egon G Guba. 1985. Naturalistic Inquiry. Vol. 75. Sage.

Lukens, Jonathan, and Carl DiSalvo. 2011. "Speculative Design and Technological Fluency." International Journal of Learning and Media 3 (4): 23-40. doi:10.1162/IJLM_a_00080.

Sanders, Elizabeth B.-N., and Pieter Jan Stappers. 2008. "Co-Creation and the New Landscapes of Design." CoDesign 4 (1): 5-18. doi:10.1080/15710880701875068.

Sanoff, Henry. 2008. “Multiple Views of Participatory Design.” International Journal of Architectural Research 2 (1): 57-69. 
Wakkary, Ron, William Odom, Sabrina Hauser, Garnet Hertz, and Henry Lin. 2015.

"Material Speculation: Actual Artifacts for Critical Inquiry." Aarhus Series on Human Centered Computing 1 (1): 12. doi:10.7146/aahcc.v1i1.21299. 